\title{
CORRIGENDA
}

\section{Progress and prospects: gene therapy clinical trials (part 1)}

Gene Therapy (2007) 14, 1754; doi:10.1038/sj.gt.3303075

Correction to: Gene Therapy (2007) 14, 1439-1447; doi:10.1038/sj.gt.3303001

The list of authors was omitted from this paper. All authors contributed equally to this work and are listed in alphabetical order. The correct author listing should be as follows:

BL Alexander ${ }^{1}$, RR Ali ${ }^{2}$, EWFW Alton ${ }^{3}$, JW Bainbridge ${ }^{2}$, S Braun ${ }^{4}$ SH Cheng ${ }^{5}$, TR Flotte ${ }^{6}$ HB Gaspar ${ }^{7}$, M Grez ${ }^{8}$, U Griesenbach ${ }^{3}$, MG Kaplitt ${ }^{1}$, MG Ott ${ }^{9}$, $\mathrm{R}$ Seger ${ }^{10}, \mathrm{M} \mathrm{Simons}^{11}$, AJ Thrasher ${ }^{7}$, AZ Thrasher ${ }^{7}$ and S Ylä-Herttuala ${ }^{12}$

\begin{abstract}
${ }^{1}$ Laboratory of Molecular Neurosurgery, Weill Cornell Medical College, NY, USA; ${ }^{2}$ Division of Molecular Therapy, UCL Institute of Ophthalmology, London, UK; ${ }^{3} \mathrm{On}$ behalf of the UK Cystic Fibrosis Gene Therapy Consortium; ${ }^{4}$ Association Française contre les Myopathies (AFM), Evry, France; ${ }^{5}$ Genzyme Corporation, Framingham, MA, USA; ${ }^{6}$ University of Massachusetts, Medical School, Worcester, MA, USA; ${ }^{7}$ Molecular Immunology Unit, Institute of Child Health, UCL, London, UK; ${ }^{8}$ Georg-Speyer-Haus, Frankfurt, Germany; ${ }^{9}$ Department of Hematology, University Medical School, Frankfurt, Germany; ${ }^{10}$ Kinderspital Zurich, Zurich, Switzerland; ${ }^{11}$ Dartmouth Medical School, Hanover, NH, USA and ${ }^{12}$ Kuopio University, Kuopio, Finland
\end{abstract}

\section{Progress and prospects: gene therapy clinical trials (part 2)}

Gene Therapy (2007) 14, 1754; doi:10.1038/sj.gt.3303076

Correction to: Gene Therapy (2007) 14, 1555-1563; doi:10.1038/sj.gt.3303033

The list of authors was omitted from this paper. All authors contributed equally to this work and are listed in alphabetical order. The correct author listing should be as follows:

A Aiuti ${ }^{1}$, A-C Bachoud-Lévi², A Blesch ${ }^{3}$, MK Brenner ${ }^{4}$, F Cattaneo ${ }^{1}$, EA Chiocca ${ }^{5}$, G Gao ${ }^{6}$, KA High ${ }^{7}$, AM Leen ${ }^{4}$, NR Lemoine ${ }^{8}$, IA McNeish ${ }^{8}$, G Meneguzzi ${ }^{2}$, M Peschanski ${ }^{2}$, MG Roncarolo ${ }^{1}$, DS Strayer ${ }^{9}$, MH Tuszynski ${ }^{3,10}$, DJ Waxman ${ }^{11}$ and JM Wilson ${ }^{6}$

${ }^{1}$ Pediatric Clinical Research Unit, San Raffaele Telethon Institute for Gene Therapy (HSR-TIGET), Milano, Italy;
${ }^{2}$ INSERM, University of Nice-Sophia Antipolis, Nice, France; ${ }^{3}$ Department of Neurosciences, University of California, San Diego, La Jolla, CA, USA; ${ }^{4}$ Center for Cell and Gene Therapy, Baylor College of Medicine, Texas Children's Hospital and The Methodist Hospital, Houston, TX, USA; ${ }^{5}$ The Ohio State University Medical Center, Columbus, OH, USA; ${ }^{6}$ Gene Therapy Program, Department of Pathology and Laboratory Medicine, University of Pennsylvania, Philadelphia, PA, USA; ${ }^{7}$ The Children's Hospital of Philadelphia, Philadelphia, PA, USA; ${ }^{8}$ Centre for Molecular Oncology, Barts and the London, Queen Mary's School of Medicine and Dentistry, London, UK; ${ }^{9}$ Department of Pathology, Jefferson Medical College, Philadelphia, PA, USA; ${ }^{10}$ Veterans Administration Medical Center, San Diego, CA, USA and ${ }^{11}$ Boston University, Boston, MA, USA 